
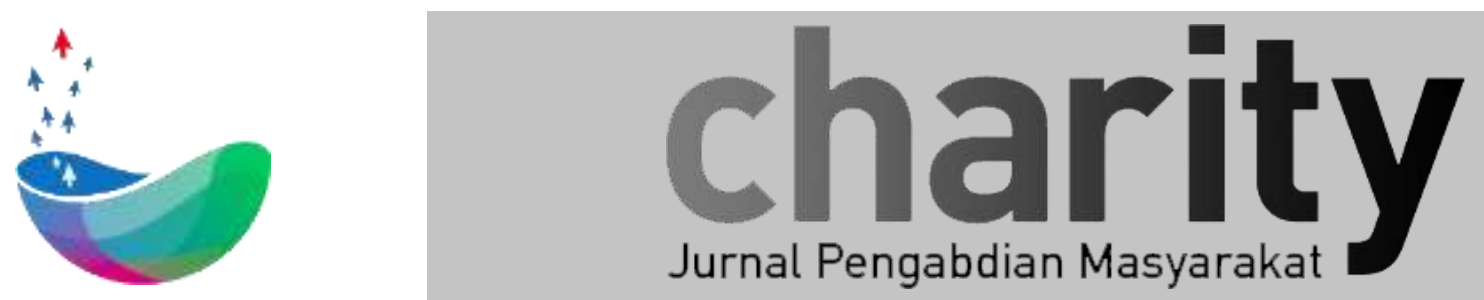

\title{
PENINGKATAN PENDAPATAN PENDAPATAN DAN DAYA SAING UMKM MELALUI PENGUATAN BRAND DAN PEMASARAN DIGITAL SIAP PAKAI PADA KECAMATAN CIKANCUNG
}

\author{
Rahmat hidayat ${ }^{1}$. Ati Mustikasari ${ }^{2,}$ Leni Cahyani ${ }^{3}$ \\ Program Studi Manajemen Pemasaran, Fakultas Ilmu Terepan, Universitas Telkom \\ Program Studi Manajemen Pemasaran, Fakultas Ilmu Terepan, Universitas Telkom \\ Program Studi Manajemen Pemasaran, Fakultas Ilmu Terepan, Universitas Telkom \\ rahmathidayat@tass.telkomuniversity.ac.id
}

\section{INFO ARTIKEL}

Diterima 26 Juni 2019

Direvisi 3 Juli 2019

Disetujui 30 Agustus 2019

Tersedia Online 9 September 2019

\section{Keyword : UMKM, HKI,CIkancung}

\begin{abstract}
ABSTRAK
Tantangan jenis produk yang dihasilkan oleh UMKM pada saat ini untuk masuk ke pasar nasional maupun internasional masih mengalami kendala terutama di daerah Kecamatan Cikancung, selain dikarenakan produk yang dihasilkannya belum berdaya saing tinggi kemungkinan dikarenakan belum memenuhi selera pasar pada saat ini Sehingga tujuan dari kegiatan pengabdian ini adalah untuk membantu UMKM di Kecamatan Cikancung dalam menghasilkan produk yang berdaya saing tinggi dan dapat memenuhi selera pasar.

Adapun metode yang digunakan pada kegiatan pengabdian ini adalah dengan memberikan penyuluhan dan pelatihan yang berkaitan dengan website, brand, produk dan $\mathrm{HKI}$, dengan peserta yang diundang adalah para pengrajin yang berasal dari Kecamatan Cikancung sebanyak kurang lebih 100 orang. Hasil dari kegiatan pengabdian ini diharapkan adanya peningkatan pengetahuan dan kemampuan dari para UMKM di Kecamatan Cikancung yang berkaitan website, brand, produk dan HKI.
\end{abstract}

Korespondensi :

Direktorat Penelitian dan Pengabdian Masyarakat, Universitas Telkom

Jl. Telekomunikasi No. 1, Terusan Buah Batu, Bandung, 40257

Indonesia.

E-mail: charity@ telkomuniversity.ac.id

ORCID ID: 0000-0003-1937-7767

Penulis Pertama: Rahmat Hidayat

https://doi.org/10.25124/charity.v1i01.1572

Paper_reg_number 2063 ㅇ The Authors. Published by Directorate of Research and Community Service, Telkom University.

This is an open access article under the CC BY-NC 4.0 license (https://creativecommons.org/licenses/by-nc/4.0/) 


\section{PENDAHULUAN}

Kecamatan adalah bagian wilayah dari kabupaten/ kota yang dipimpin oleh camat. Hal ini sesuai dengan ketentuan pasal 1 angka 24 undang-undang Republik indonesia Nomor 23 Tahun 2014 Tentang pemerintah daerah yang menyatakan bahwa :kecamatan atau yang disebut dengan nama lain adalah bagian wilayah dari daerah/ kota yang dipimpin oleh camat (wikipedia.: 2018). Kecamatan Cikancung merupakan salah satu Lokasi yang berada di Kabupaten Bandung, provinsi Jawa Barat yang memiliki 9 Kelurahan, Dengan jumlah UMKM sebanyak 15 pengrajin dengan berbagai produk yang dihasilkan dan sudah diresmikan oleh pemerintah kabupaten sebagai kampung bibika dengan rencana bupati kabupaten bandung adanya setiap kampung memiliki ciri khas yang bisa menonjolkan produk unggulan sebagai sektor wisata, maupun industri. Sehingga kolaborasi antara akademik dan pemerintah selaras dengan mengembangkan edukasi kepada masyarakat khususnya di kecamatan cikancung selain kampung bibika.

Dalam rangka menuju program seribu kampung, Pemerintah Daerah telah dan sedang menyiapkan beberapa program kampung, yakni kampung digital, hidroponik, budaya, kampung keluarga berencana, dan kampung tematik, salah satunya kampung bibika di Desa Cihanyir. Dengan produksinya bisa lebih canggih, dengan memanfaatkan teknologi yang ada. Selain produksi, kemasan juga pemasarannya harus lebih baik, Misalnya pemasaran secara online, sehingga bisa lebih banyak dikenal masyarakat luas, bahkan hingga mancanegara ( JabarNews.com :2018).

Penerapan informasi kepada masyarakat mengenai pentinya inovasi produk pada suatu daerah agar bisa berkembang di bisang ekomoni dan meningkatnya kesejahteraan masyarakat sehingga tujuan pengabdian masyarakat ini mengembangkan potensi masyarakat cikancung melalui pemasaran digital yang siap pakai dan berkolaborasi dari dengan pemerintah setempat yaitu kecamatan. Produk luar negri (impor) mempengaruhi produk lokal yang bisa menurunkan potensi perekonomian masyarakat dikarenakan hasil produksi dan penjualan menurun.

Pembangan masyarakat daerah pesisir pegunungan yang harus meningkat kualitas hidupnya sehingga bisa mengejar ketertinggalan dari daerah lain. Salah satunya Produk lokal dari cikancung yaitu ranginang yang pada saat ini kurang diperhatikan dan tidak ada dipasarkan ditempat ritel (Supermaket atau mimnimarket) sehingga pengembangan yang dibutuhkan baik dari segi kemasan, pemasaran digital maka peran dari akademisi untuk membantu masyarakat dalam inovasi produk ciri khas cikancung. Harapan dari pihak pemerintah agar dari hasil inovasi produk cikancung ini bisa dijadikan sebagai oleh=oleh khas bandung kecamatan cikancung.

Pemanfaatan teknologi informasi dan komunikasi pada masyarakat cikancung merupakan media yang utama, dengan system informasi yang dimiliki daerah tersebut. Hal ini bisa dimanfaatkan dalam mengembangkan produk yang dibuat dan optimalisasi dari Sumber daya yang ada seperti Karang taruna bisa memperkenalkan produk yang dibuat oleh masyarakat cikancung dengan media teknologi dengan pengawasan pihak UMKM/ Pemerintah setempat. Harpan pengabdian masyarakat ini unruk mengembangkan masyarakat dalam memanfatkan Teknologi sebagai media pemasaran dan meningktakan kualitas sumber daya manusia yang siap.

\section{MASALAH}

Permasalahan yang mereka hadapi hampir memiliki kesamaan yaitu rendahnya daya saing karena produk yang dihasilkannya hampir tidak memiliki keunikan atau kelebihan dibanding produk pesaig, terbatasnya pangsa pasar karena pengetahuan terhadap pemanfaatan teknologi internet masih sangat rendah, mayoritas belum memiliki brand atau merek jual sendiri sehingga dari permasalahan yang mereka hadapi mengakibatkan pada rendahnya tingkat brand 
awareness yang terbentuk. Sehinggan kemasan dalam pengembangkan produk perlu ditingkatkan lebih baik lagi.

\section{METODE KEGIATAN}

\subsection{Metode Kegiatan Pengabdian}

Metode yang digunakan dalam acara pengabdiaan masyarakat ini adalah dengan memberikan pelatihan/penyuluhan guna mengembangkan potensi yang dimiliki oleh mitra dan menjawab permasalahan dari solusi pengrajin yang ada di Kecamatan Cikancung.Teknik yang digunakan melalui wawancara kepada pemerintah desa dan para pengrajin didesa sana sehingga informasi yang diberikan bisa memenuhi kebutuhan dan menyelesaikan permasalahan yang dihadapi para pengrajin. Masyarakat sasaran pada program pengabdian masyarakat adalah pelaku usaha kecil . namun banyak hal yang masih terkendala dan perlu pengembangan inovasi diberbagai bidang yang mendukung proses kelancaran usaha yang di jalaninya.

Konsultasi bertujuan dalam memberikan ruang kemudahan kepada masyarakat cikancung jika terjadi kendala yang dihadapi dalam mengembangkan produk baik secara pengolahan, teknologi dan pemasaran yang langsung kepada Tim akdemisi.
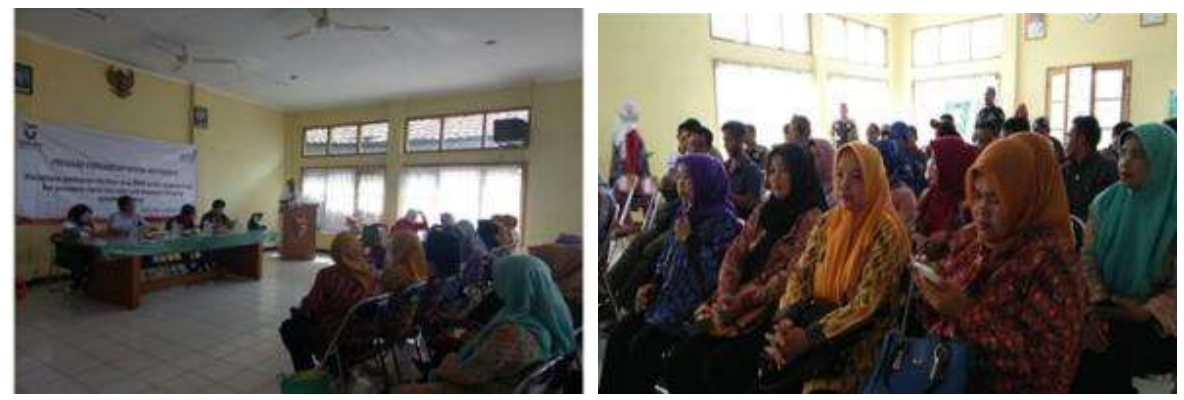

\subsection{Teknik Pengumpulan Data}

Pengumpulan data dilakukan dengan teknik pengambilan data berupa pertanyaan dari wawancara dan observasi.

\subsection{Teknik Analisis Data}

Teknik analisis data yang dilakukan adalah deskriptif kuantitatif, bertujuan untuk mendapatkan gambaran karakteristik penduduk dan kondisi perekonomian masyarakat kecamatan cikancung.

\subsection{Lokasi, Waktu, dan Durasi Kegiatan}

Kegiatan akan dilaksanakan di balai pertemuan kecamatan cikancung kabuapten Bandung, Jawa Barat di tahun 2018.

\section{ANALISA HASIL KEGIATAN}

Solusi yang akan diberikan dengan kegiatan ini adalah sebagai berikut: 
1. Memberikan pelatihan kepada para UKM dalam menciptakan produk unggulan baru atau menambahkan value baru yang memiliki kearifan lokal budaya setempat sehingga menjadi produk ungggulan yang khas daerah tersebut.

2. Memberikan penyuluhan bagaimana membuat sebuah merk baik dari segi gambar, tulisan dan makna serta bagaimana menguatkan branding yang telah mereka miliki.

3. Memberikan penyuluhan/pelatihan pemanfaatan internet dan pembuatan website untuk para UKM sebagai media pemasaran yang efektif

4. Memberikan penyuluhan tentang HAKI, agar tidak terjadi pengakuan produk mereka oleh orang lain.

Adapun skema yang akan diberikan kepada peserta pelatihan dengan metode yang menunjang kegiatan pengabdiaan masyarakat dan memberikan kontribusi kepada masyarakat untuk mengubah proses menjual dan mengolah produk menjadi layak dijual dan menjadi bandung timur

Luaran dari pengabdian masyakat yang akan kami laksanakan antara lain: Jasa Pelatihan/Penyuluhan Tentang Produk, branding, pemasaran digital dan HAKI yang diharapkan peserta selain dapat pengetahuannya juga dapat menambah wawasan tentang bagaimana meningkatkan value produk dan memasukkan unsur kearifan budaya lokal sehingga menjadi produk unggulan yang memiliki daya saing. Membuat brand yang kuat diingat oleh pasar baik dalam bentuk, warna, gambar, makna dll yang menjadi identitas kuat para UKM. Menggunakan pemasaran digital secara efektif dan optimal melalui website yang telah kami bantu. Mengajukan HAKI untuk produk yang mereka miliki, agar tidak terjadi pengakuan produk mereka oleh orang lain.

\subsection{Kegiatan}

Rekomendasi untuk kegiatan pengabdian masyarakat selanjutnya adalah dibangunnya kesadaran masyarakat akan manfaat dari program yang telah diberikan dan adanya penyesuaian dengan kebiasaan masyarakat. Selain itu diperlukan adanya komunikasi yang intens kepada masyarakat dan evaluasi yang terstruktur.

\section{Hasil Pengabdian kepada Masyarakat}

\section{a. Inovasi Produk Makanan kuliner}

Pengolahan kuliner asal cikancung salah satunya dalah ranginang yang secara tektur prodaknya besar seperti piring maka dengan inovasi produk yang mudah dipasarkan adalah dengan bentuk yang kecil dengan bervariasi rasa yang bisa dinikmati oleh para kuliner dan pengolahan secara manual (tradisional ) itu yang membedakan rasa produk ranginang cikancung.

Pengawet makanan kimia bisa mempengaruhi rasa dan kepercayaan konsumen dalam membeli produk dan lebih disarankan pengawet atau perwana makanan yang tradisional seperti :Aroma dalam makan Aroma Natural Ekstraksi dari sayuran, buah dan hewan contohnya vanila extrak, esens buah (1) Rempah - Rempah Kayu manis, Cengkeh, Ketumbar, Jinten, Pala, Merica Hitam, Saffron, Paprika Powder. (2) Olahan Terasi.

\section{b. Kemasan \& Aspek promosi pada kemasan}

Desain kemasan berlaku pada sutau produk untuk mengenali indentitas sehingga bisa digunakan sebagai pelindung makanan, pengiriman produk, dan membedakan sebuah produk dipasar dengan produk lain. desain kemasan sebagai strategi pemasaran produk dengan menyampaikan pribadi produk atau fungsi produk yang unik. Logo atau tanda gambar merupakan identitas yang dipergunakan untuk menggambarkan citra dan karakter suatu lembaga atau perusahaan maupun organisasi. Pada prinsipnya logo merupakan symbol yang mewakili sosok, wajah, dan eksistensi suatu perusahaan atau produk perusahaan Selain membangun citra, logo juga seringkali dipergunakan untuk 
membangun spirit secara internal dan diantara komponen yang ada dalam perusahaan tersebut.

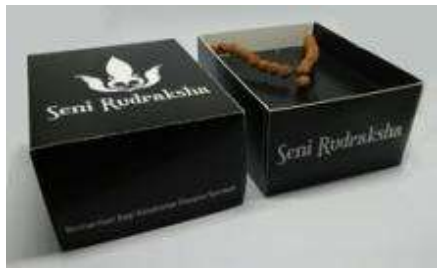

\section{c. Brand (ing) Antara Indentitas dan nilai}

Sekumpulan aset fisik dan non fisik dari sebuah produk, jasa atau lembaga sehingga bisa teridenfikasi kekhasannya atau keunikannya. (Landor) Brand sepekotak memori yang ada di benak kita yang dipengaruhi oleh: Pengalaman akan produk tertentu, Pengalaman karena membeli, Kekuatan dari citra lembaga dan Aktvitas periklanan. Proses formulasi brand iden)ty agar proses pembentukannya bisa terkendali dan upaya untuk menjaga konsistensi brand agar persepsi yang terbentuk dari brand image dapat tetap terjaga dengan baik.

\section{Daftar Pustaka}

Jabarnews.com/2018/07/ada-kampung-bibika-di-cikancung-kabupaten-bandung.html https://id.wikipedia.org/wiki/Kecamatan 


\section{LAMPIRAN}

Foto Kegiatan
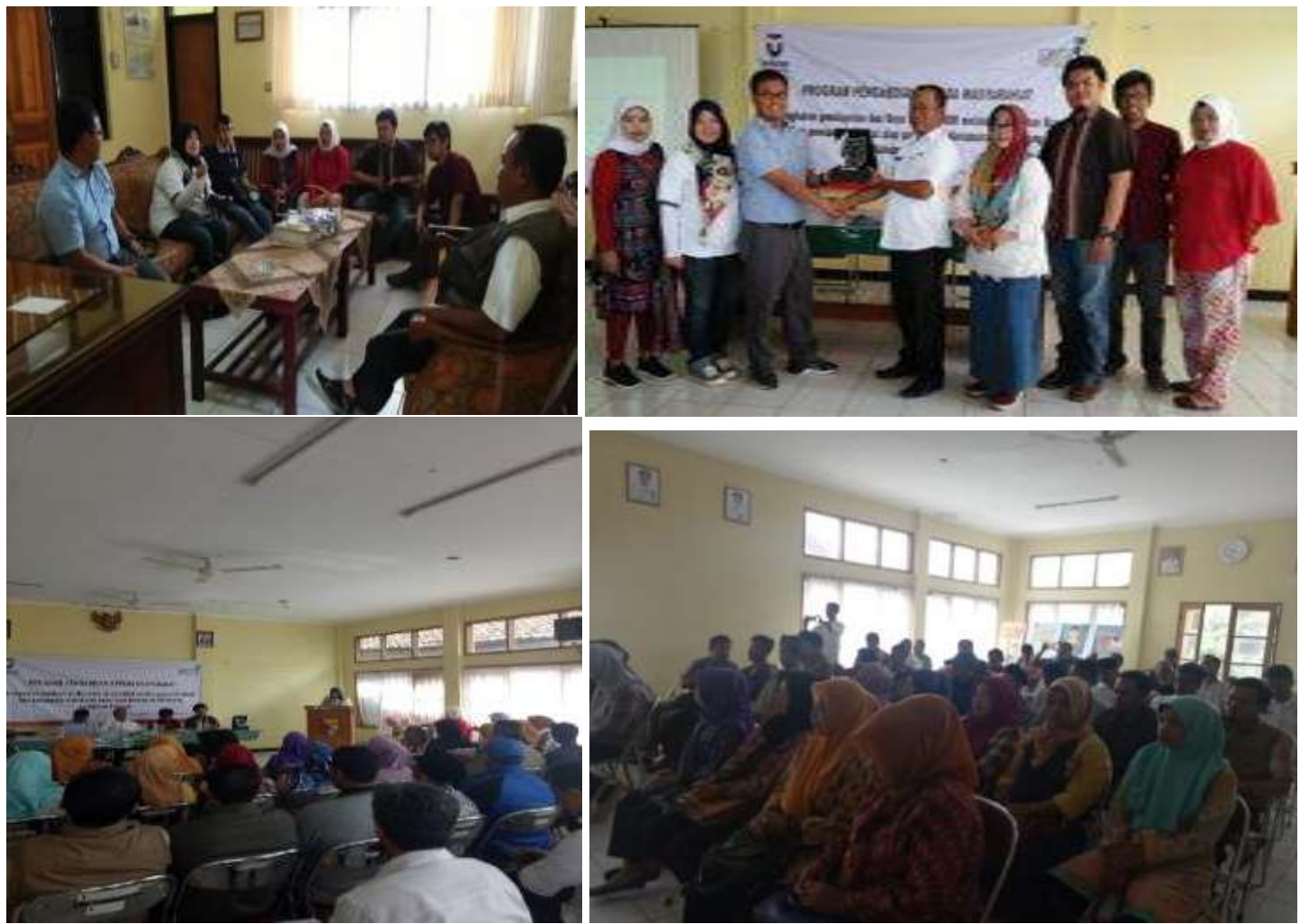

Biodata Narasi Singkat 